\title{
Comorbidity in Post-traumatic stress disorder: A population-based study from the two largest cities in Brazil
}

Authors

\section{Márcio Souto de Castro Longo (Corresponding Author)}

Residency Program in Family and Community Medicine, Secretaria Municipal de Saúde do Estado do Rio de Janeiro (RJ), Brazil

E-mail: msc.longo@gmail.com

Rua Gago Coutinho 28/203 - Laranjeiras

Rio de Janeiro - RJ - Brazil

CEP 22221-070

Liliane Maria Pereira Vilete

Universidade Federal do Rio de Janeiro, Instituto de Psiquiatria, Rio de Janeiro, Brazil

Ivan Figueira

Universidade Federal do Rio de Janeiro, Instituto de Psiquiatria, Rio de Janeiro, Brazil

Maria Inês Quintana

Universidade Federal de São Paulo, Departamento de Psiquiatria, São Paulo, Brazil

Marcelo Feijó Mello

Universidade Federal de São Paulo, Departamento de Psiquiatria, São Paulo, Brazil

Rodrigo A. Bressan, MD PhD

Department of Psychosis Studies, Institute of Psychiatry, Psychology and Neuroscience King's College London, UK

Jair de Jesus Mari

Universidade Federal de São Paulo, Departamento de Psiquiatria, São Paulo, Brazil

Wagner Silva Ribeiro, PHD

Personal Social Services Research Unit, London School of Economics and Political Science, London, UK

\section{Sergio Baxter Andreoli}

Universidade Federal de São Paulo, Departamento de Psiquiatria, São Paulo, Brazil

\section{Evandro Silva Freire Coutinho}

Fundação Oswaldo Cruz, Escola Nacional de Saúde Pública, Rio de Janeiro, Brazil

Instituto de Medicina Social da Universidade do Estado do Rio de Janeiro, Rio de Janeiro, Brazil 


\begin{abstract}
Background: This study investigated the patterns of comorbidity between PTSD and depression, other anxiety disorders, alcohol-related disorders using the DSM-IV and ICD-10 criteria. The temporal sequence of the comorbid diagnoses was also investigated.

Methods: We used data from a large population-based survey carried out between 2007 and 2008 in the two largest cities in Brazil: São Paulo and Rio de Janeiro.

Results: Diagnoses of depression, other anxiety disorders, and alcohol-related disorder were more prevalent in the people with PTSD than in those without PTSD. Using the DSM-IV criteria, approximately $67 \%$ of cases presenting PTSD were also diagnosed with another mental disorder. The diagnosis category of other anxiety disorders presented the highest proportion of comorbidity (53\%). Depression was found in 34\% person with PTSD whilst alcohol-related disorders were observed in $7 \%$. Considering the temporal relationship, the onset of comorbid depression was uniformly distributed through the periods before, within the same year and after PTSD's onset. When other anxiety disorders were comorbid with PTSD, in almost $90 \%$ of the cases the other anxiety disorders preceded PTSD. For comorbidity between of alcohol-related disorders and PTSD, in $50 \%$ of the cases alcohol-related disorders preceded the diagnosis of PTSD.
\end{abstract}

Limitations: The cross-sectional design imposes limitations on establishing a temporal relationship between the onset of psychiatric disorders due to memory bias.

Conclusions: Our findings indicate that among individuals presenting comorbid PTSD and other anxiety disorders, this diagnosis tend to precede PTSD. Comorbid cases are more frequent and more severe, and this should be taken into account in therapeutic research and clinical practice.

\title{
Keywords
}

Post-traumatic stress disorder; comorbidity; a population-based study

Research Highlights

Population-based study on PTSD in Brazil's two largest cities

Comorbidity with depression, anxious and alcohol-related disorders was studied

Co-occurring diagnoses were significantly higher in the population with PTSD

Anxiety disorders accounted for $50 \%$ of comorbid cases with PTSD

Anxiety disorders initiated before PTSD in approximately $90 \%$ of comorbid cases

\section{Abbreviations}

PTSD, post-traumatic stress disorder; DSM-IV, Diagnostic and Statistical Manual - IV; ICD-10, International Classification of Diseases 


\section{Introduction}

The exposure to traumatic events is an important cause of long-term psychopathology but not exclusively related to PTSD (Ribeiro et al., 2013) and PTSD frequently overlaps with other psychiatric disorders (Kessler and Chiu, 2005; Kessler et al., 1995). The high prevalence of comorbidity in psychiatry has led to a great number of publications on the subject, as it raises conceptual problems for both clinical and psychopathological research (Krueger and Markon, 2006). Breslau (Breslau, 2002) proposed three explanatory mechanisms for the comorbidity of PTSD with other disorders.

The first mechanism states that pre-existing disorders might produce an increased risk of PTSD, either by increasing the victim's susceptibility after a traumatic event or by making the individual more likely to be exposed to traumatic events prompted by the pre-existing disorder. This mechanism is corroborated by evidence that substance use disorder increases the risk of experiencing traumatic events (Breslau, 2002; Mills et al., 2006). History of depression also increases the risk of traumatic events and life stressors (Breslau et al., 1997) and there is evidence of depression preceding PTSD when they co-occur (O'Toole et al., 1998).

The second mechanism suggests that PTSD increases the risk of developing other disorders like depression, anxiety or substance use disorders. Substance use can be a way of coping with PTSD symptoms (Breslau, 2002) and some studies found depression and anxiety to be mostly secondary to PTSD (Engdahl et al., 1998; Franko et al., 2005; Kessler et al., 1995).

According to the third mechanism proposed by Breslau, PTSD and other comorbid disorders co-occur due to shared risk factors that predispose the individual to both disorders. The common genetic factors shared by PTSD and substance use disorders are evidence for this (Breslau et al., 1997; Connor and Davidson, 1997). Exposure to trauma predisposes to both PTSD and other disorder (Friedman and Yehuda, 1995; Jordan et al., 1991; Kulka et al., 1990). The co-occurrence of PTSD with other disorders could reflect the superposition of different vulnerabilities such as child abuse/neglect, personality traits (i.e., neuroticism), and gender (Friedman and Yehuda, 1995; Spinhoven et al., 2014; Yehuda et al., 1998)

Ginzburg et al.(Ginzburg et al., 2010) propose an additional mechanism to those described by Breslau. According to these authors, comorbidity is a mere artifact of symptom overlap that is intrinsic to psychiatric classification. This argument is ratified by some studies that fail to find differences in patients with comorbid PTSD and depression compared to patients with PTSD alone in outcomes such as severity (Franklin and Zimmerman, 2001; Solomon and Bleich, 1998), functional impairment (Stein et al., 2000), or response to treatment (Labbate et al., 2004).

The present study aims to assess the co-occurrence (comorbidity) of PTSD with depression, anxiety, and alcohol-related disorders in a large community sample. It also addresses Breslau's first and second mechanism described above by reconstructing the chronology of the onset of the comorbid disorders.

\section{Material and Methods}


A cross-sectional study was carried out in 2007-2008 including a sample of individuals aged 15-75 years, living in the two largest cities of Brazil (São Paulo e Rio de Janeiro). A detailed description of the original study was done by Andreoli et al. (Andreoli et al., 2009).

\section{Sampling procedure}

The study used a multistage probability proportional to size sampling scheme. Firstly, different areas in the cities were stratified into six groups according to homicide rates. The three strata with the highest homicide rates were oversampled. Secondly, census sectors in those areas were mapped, and a number of those sectors were randomly selected in each stratum. The number of census sectors varied from 4 to 18 according to population size in each stratum. Thirdly, 43 households (in São Paulo) and 30 households (in Rio de Janeiro) were randomly selected in each census sector. In each household, all residents aged from 15 to 75 years old were enumerated and, amongst those, one was selected according to the Kish method. After considering an expected refusal rate of $20 \%$ a final sample size of 3000 and 1500 was established for São Paulo and Rio de Janeiro, respectively. Data were weighed to account for the oversampling of the most violent strata, and also for differential probability of selection.

\section{Data Collection}

Two of the authors (MIQ and WSR) were responsible for training the fieldwork team, whilst the supervision of the team included another researcher (LMV). The training process comprised a 30-hour theoretical and practical module, followed by a pilot study. In the pilot study, each interviewer conducted ten supervised interviews.

Data was collected between June/2007 and January 2008 in São Paulo and between October/2007 and July/2008 in Rio de Janeiro by a company specialized in household surveys - the Brazilian Institute of Public Opinion and Statistics (IBOPE). Every step of the fieldwork was followed by one of the authors (WSR). Each household was contacted up to 10 times if necessary, to avoid losses.

The interview included structured questionnaires and scales, all of which are widely applied in epidemiological surveys. Most of these instruments have previously been translated into Portuguese and validated to the Brazilian cultural context. Those not validated were carefully translated and adapted by the authors of the study. The whole interview lasted approximately 1.5 to 2.5 hours. Regular meetings with the supervision team were carried out to solve doubts and standardize the interview procedures. Additionally, a standardized operational procedure manual was provided to the interviewers covering all aspects of the fieldwork.

\section{Variables and measurements used in the analysis}

a) Sex and age: Age was stratified into four categories (15-29; 30-44; 45-59; 60-75).

b) Psychiatric disorders: Psychiatric disorders was accessed in the study using the Composite International Diagnostic Interview 2.1 (CIDI 2.1) (World Health Organization., 1997), a standardized, fully structured interview for diagnosis and classification of mental disorders according to the International Classification of Diseases, $10^{\text {th }}$ edition (ICD-10) (World Health Organization, 1992) and the Diagnostic and Statistical Manual of the American Psychiatric Association, $4^{\text {th }}$ Edition (DSM-IV) (American Psychiatric Association, 1994). The Brazilian Version of the CIDI 2.1 was previously validated (Quintana et al., 2007) with sensitivity and specificity for depressive disorder (82.5\%) and 
(92.8\%), phobic-anxiety disorders (80.6\% and 93.5\%) and alcohol hazardous use and dependence (79.5\% and $97.3 \%$ ) which were found to be satisfactory (Quintana et al., 2012). When compared to the Structured Clinical Interview (SCID) (Spitzer et al., 1992), the CIDI 2.1 PTSD section had a sensitivity of $82.4 \%$ and specificity $84.8 \%$ for the ICD-10 PTSD diagnostic criteria, and sensitivity of $51.5 \%$ and specificity of $94.1 \%$ for the DSM-IV criteria (Quintana et al., 2012). This study focused on the following psychiatric disorders: (i) post-traumatic stress disorder (PTSD), (ii) phobic-anxiety disorders, (iii) depression, (iv) alcohol abuse and dependence. Traumatic events used for defining PTSD was based on the CIDI 2.1's list of traumatic events.

c) Age-of-onset of each disorder, as reported by respondents.

\section{Quality Control}

The supervision team verified all questionnaires within the same week they had been applied, to correct inconsistencies and check veracity. The supervisors re-interviewed at least $20 \%$ of all the participants.

\section{Statistical Analyses}

All statistical analyses were conducted considering two systems of classification: the ICD-10 and DSM-IV. This decision was made considering the CIDI 2.1's differences in sensitivity and specificity for the PTSD diagnosis between the ICD-10 ( $82.4 \%$ and $84.8 \%$ respectively) and the DSMIV (51.5\% and $94.1 \%$ respectively). Twelve-month prevalence rates and their respective $95 \%$ confidence intervals were estimated for each of the three major groups of mental disorders depression, other anxiety disorders (PTSD excluded), and alcohol-related disorders - in all individuals regardless of the co-occurring diagnosis of PTSD.

Comorbidity was estimated by calculating the proportion of participants with PTSD presenting at least an additional mental disorder.

The temporal relationship of depression, other anxiety disorders and alcohol-related disorders with PTSD were classified as previous to PTSD, concurrent (same year) or subsequent to PTSD. To carry out this analysis, we first created a dummy variable (0: no; 1 : yes) that was coded as 1 when PTSD diagnosis co-occurred with one of each of the diagnosis within the three major groups described above. Only data on 12-month prevalence was used. This means that only the disorders that were still present by the time of the interview were considered in the analysis, but the age-ofonset could be at any time in the past. Lifetime prevalence data on disorders which had remitted before the time of the interview was not used as it was considered to be less reliable and more subject to memory bias.

Secondly, using the age of onset of each disorder we used the formula:

\section{Age-of-onset of PTSD - (minus) Age-of-onset of Comorbidity}

Negative values meant that the comorbidity initiated after the onset of PTSD whereas positive values meant that the comorbidity was before PTSD onset. Values equal to 0 (zero) were considered, in this study, as evidence that both disorders had the same age of onset (same year). 
This procedure was repeated for each diagnosis within the three major groups: depression, other anxiety disorders, and alcohol-related disorders. Considering that more than one cooccurrence of diagnoses (i.e., simple phobia + panic disorder) could be present within a diagnostic category (i.e., other anxiety disorders), we chose the diagnosis with the earliest age-of-onset within each group. A similar methodology was used by Engdahl et al., to retrospectively reconstruct the temporal relationship between PTSD and other disorders in the study with Australian Vietnam War Veterans (Engdahl et al., 1998).

All statistical analyses were performed with STATA version 12 and used the svy command for complex sampling design.

\section{Ethical Issues}

The study was approved by the São Paulo's Federal University Ethics Committee. The interviews were only initiated after the respondents signed the informed consent form. If the selected individual was aged between 15 and 17 years old, their parents or legal representatives were asked to sign the informed consent form as well. A phone number was provided in case a participant wanted to be referred to a specialized service.

\section{Results}

\section{Sample Characteristics}

We interviewed 2,536 individuals in São Paulo and 1,208 in Rio de Janeiro, and response rates were 85 and $81 \%$ respectively. There was a slight, but non-significant preponderance of women (57.7\%) and $52.1 \%$ of the sample was aged between 15 and 35 years. Most of the interviewees were married (55,5\%) and employed (59,2\%) (Table 1). The Rio de Janeiro sample was older on average and had higher mean years-of-schooling. This reflected the fact that in São Paulo the more violent areas were over-represented for the study purposes. About one-third of the sample had 9 to 12 schooling. More than $80 \%$ of the sample reported traumatic experiences that could potentially lead to PTSD. The most frequent were: the sudden unexpected death of a close person, seeing or touching a corpse unexpectedly, being attacked with a weapon, witnessing someone being killed or injured, witnessing crime organization's attacks (Ribeiro et al., 2013). ICD10 12-month prevalence of PTSD was 8.7\% (95\% Cl: 7.4-10.3) and for DSM-IV 12-month prevalence was $4.5 \%$ ( $95 \% \mathrm{Cl}: 3.6-5.7)$. Prevalence on other mental disorders can be found in (Ribeiro et al., 2013). 
Table 1. Demographic characteristics of the sample in São Paulo and Rio de Janeiro, Brazil, $2007-2008$.

\begin{tabular}{|c|c|c|c|}
\hline & $\begin{array}{l}\text { São Paulo } \\
\mathrm{N}=2.536 \\
\% \text { (IC 95\%) }\end{array}$ & $\begin{array}{l}\text { Rio de Janeiro } \\
\qquad \mathrm{N}=1.208 \\
\% \text { (IC } 95 \%)\end{array}$ & $\begin{array}{c}\text { Total } \\
\% \text { (IC 95\%) }\end{array}$ \\
\hline \multicolumn{4}{|l|}{ GENDER } \\
\hline Female & $58.1(56.2-59.9)$ & $56.6(54.3-58.9)$ & $57.7(56.2-59.1)$ \\
\hline Male & $41.9(40.1-43.8)$ & $43.4(41.1-45.7)$ & $42.3(40.9-43.8)$ \\
\hline \multicolumn{4}{|l|}{ AGE (Years) } \\
\hline $15-29$ & $38.8(35.6-42.1)$ & $32.8(29.7-36.0)$ & $37.1(34.6-39.6)$ \\
\hline $30-34$ & $16.2(14.3-18.4)$ & $11.9(9.6-14.6)$ & $15.0(13.4-16.8)$ \\
\hline $35-59$ & $30.1(27.1-33.3)$ & $33.1(30.0-36.4)$ & $31.0(28.6-33.4)$ \\
\hline $60-75$ & $14.9(13.0-17.0)$ & $22.2(19.0-25.8)$ & $17.0(15.2-18.9)$ \\
\hline Mean (SD) & 39.5 (38.5 - 40.5) & $42.4(41.0-43.5)$ & $40.3(40.0-41.1)$ \\
\hline \multicolumn{4}{|l|}{ MARITAL STATUS } \\
\hline Single & $28.3(25.4-31.4)$ & $31.4(28.7-34.1)$ & $29.2(26.9-31.6)$ \\
\hline Married/Cohabiting & $56.9(53.4-60.3)$ & $51.9(48.2-55.6)$ & $55.5(52.7-58.2)$ \\
\hline Widowed & $5.8(4.7-7.2)$ & $0.6(4.8-7.5)$ & $5.9(5.0-6.9)$ \\
\hline Separated/Divorsed & $9.0(7.8-10.4)$ & $10.7(8.8-13.0)$ & $9.5(8.4-10.7)$ \\
\hline \multicolumn{4}{|l|}{$\begin{array}{l}\text { EDUCATION } \\
\text { (YearsofSchooling) }\end{array}$} \\
\hline None & $2.9(2.1-3.8)$ & $1.6(0.8-3.1)$ & $2.5(1.9-3.3)$ \\
\hline $1-4$ & $17.2(14.7-19.9)$ & $13.0(1.1-15.5)$ & $16.0(14.1-18.0)$ \\
\hline $5-8$ & $25.5(22.4-29.0)$ & $23.1(19.8-26.7)$ & $24.8(22.4-27.5)$ \\
\hline $9-12$ & $38.9(36.6-41.3)$ & $41.1(37.2-45.2)$ & $39.5(37.5-41.6)$ \\
\hline 13 or more & $15.6(11.4-21.0)$ & $21.2(16.5-26.8)$ & $17.2(13.8-21.2)$ \\
\hline Mean (SD) & $8.9(8.4-9.5)$ & $9.8(9.2-10.4)$ & $9.2(8.8-9.6)$ \\
\hline \multicolumn{4}{|l|}{ EMPLOYED AT THE TIME } \\
\hline OF THE INTERVIEW & $60.3(57.9-62.7)$ & $56.4(52.9-59.9)$ & $59.2(57.2-61.2)$ \\
\hline
\end{tabular}

(Ribeiro et al., 2013)

\section{PTSD and Comorbidity}

Table 2 shows the prevalence of comorbidity according to ICD-10 criteria. Anxiety disorders were the most frequently comorbid with PTSD being approximately 3.1 times (47.2/15.0) more frequent amongst individuals with PTSD than in individuals without the disorder. Although less prevalent in our population than anxiety disorders, depressive disorders category was the one with the greater differential among those with and without PTSD. The prevalence of depressive disorders in the PTSD group was approximately 3.8 times (28.7/7.5) higher than in individuals without PTSD. The PTSD group also had a higher prevalence of alcohol-related disorders. 
Table 2. Twelve-month prevalence of comorbidity and respective $95 \%$ confidence intervals in cases with and without PTSD, using ICD-10 criteria.

\begin{tabular}{|c|c|c|c|}
\hline $\begin{array}{l}\text { DISORDER (ICD-10) } \\
\text { COMORBIDITY (PAST } 12 \text { MONTHS) }\end{array}$ & $\begin{array}{c}\text { YES } \\
(\mathrm{N}=317) \\
\%(\text { IC } 95 \%)\end{array}$ & $\begin{array}{c}\text { No } \\
(\mathrm{N}=3427) \\
\%(I C 95 \%)\end{array}$ & $p$-value \\
\hline $\begin{array}{l}\text { DEPRESSIVE DISORDERS } \\
\text { Depressive episode } \\
\text { Recurrent depression } \\
\text { Dysthymia }\end{array}$ & $\begin{array}{c}28.7(23.1-35.0) \\
22.6(17.8-28.2) \\
4.7(2.8-7.8) \\
5.9(3.4-9.8)\end{array}$ & $\begin{array}{l}7.5(6.5-8.7) \\
4.4(3.6-5.3) \\
1.9(1.3-2.7) \\
2.4(1.8-3.1)\end{array}$ & $\begin{array}{l}<0.01 \\
<0.01 \\
<0.01 \\
<0.01\end{array}$ \\
\hline $\begin{array}{l}\text { OTHER ANXIETY DISORDERS } \\
\text { Panic disorder } \\
\text { Agoraphobia (without panic) } \\
\text { Specific phobia } \\
\text { Social phobia } \\
\text { Generalised anxiety disorder } \\
\text { Obsessive-compulsive disorder }\end{array}$ & $\begin{array}{c}47.2(41.5-53.0) \\
2.0(1.0-4.2) \\
8.5(5.5-13.0) \\
20.6(15.7-26.5) \\
8.8(5.5-13.8) \\
10.3(6.9-15.3) \\
5.7(3.3-9.7)\end{array}$ & $\begin{array}{c}15.0(13.6-16.6) \\
0.3(0.1-0.5) \\
1.8(1.3-2.5) \\
7.7(6.6-8.8) \\
\mathbf{3 . 6}(2.9-4.5) \\
2.9(2.3-3.7) \\
0.9(0.6-1.4)\end{array}$ & $\begin{array}{l}<0.01 \\
<0.01 \\
<0.01 \\
<0.01 \\
<0.01 \\
<0.01 \\
<0.01\end{array}$ \\
\hline $\begin{array}{l}\text { ALCOHOL } \\
\text { Dependence syndrome } \\
\text { Harmful use }\end{array}$ & $\begin{array}{l}8.3(5.3-12.7) \\
6.0(3.8-9.5) \\
2.2(0.9-5.8)\end{array}$ & $\begin{array}{l}2.4(1.8-3.3) \\
1.1(0.8-1.7) \\
1.3(0.9-1.9)\end{array}$ & $\begin{array}{c}<0.01 \\
<0.01 \\
0.31\end{array}$ \\
\hline $\begin{array}{l}\text { DUAL COMORBIDITY - PTSD + } 2 \\
\text { Depression + Anxiety } \\
\text { Depression + Alcohol } \\
\text { Anxiety + Alcohol }\end{array}$ & $\begin{array}{c}20.6(16.3-25.8) \\
2.5(1.1-5.9) \\
5.6(3.0-10.3)\end{array}$ & $\begin{array}{l}3.4(2.7-4.2) \\
0.4(0.2-0.8) \\
0.8(0.5-1.4)\end{array}$ & $\begin{array}{l}<0.01 \\
<0.01 \\
<0.01\end{array}$ \\
\hline PTSD WITH COMORBIDITY & $56.9(51.8-62.5)$ & ---- & ---- \\
\hline
\end{tabular}

Table 3 shows the same analysis, but using DSM-IV diagnostic criteria. Again, anxiety disorders are the commonest comorbid disorder with PTSD being 3.3 times (53.1/16.2) more frequent amongst those with PTSD than in individuals without the disorder. Depressive disorders demonstrated a higher prevalence of the disorders among those also diagnosed with PTSD, and in this case, the prevalence ratio between the two groups was slightly larger (4.6 fold (34.2/7.4)) than that of the ICD-10 (3.8 fold). Alcohol-related disorders according to the DSM-IV showed a smaller prevalence ratio of prevalence between the two groups being 2.5 times (7.4/3.0) higher.

Results for both classification systems were also stratified by gender, but no statistically significant results were found. As absolute frequencies fell largely when data were stratified by gender, the statistical power was too small to detect differences in these groups. The total number of cases of PTSD present in the previous 12 months was 166 cases for the DSM-IV and 317 cases for 
the ICD-10. This difference is mostly due to differences in sensitivity and specificity of each classification for PTSD as mentioned in Material and Methods.

Table 3. Twelve-month prevalence of comorbidity and respective $95 \%$ confidence intervals in cases with and without PTSD, using DSM-IV criteria.

\begin{tabular}{|c|c|c|c|}
\hline \multirow{2}{*}{$\begin{array}{l}\text { DISORDER (DSM-IV) } \\
\text { COMORBIDITY (PAST } 12 \text { MONTHS) }\end{array}$} & \multicolumn{2}{|c|}{ PTSD } & \multirow[b]{2}{*}{$p$-value } \\
\hline & $\begin{array}{c}\text { YES } \\
(\mathrm{N}=166) \\
\%(\text { IC } 95 \%)\end{array}$ & $\begin{array}{c}\text { No } \\
(\mathrm{N}=3578) \\
\%(\mathrm{IC} 95 \%)\end{array}$ & \\
\hline DEPRESSIVE DISORDERS & $34.2(27.2-41.8)$ & $7.41(6.44-8.5)$ & $<0.01$ \\
\hline Depressive episode & $28.5(22.0-36.0)$ & $4.89(4.09-5.8)$ & $<0.01$ \\
\hline Recurrent depression & $5.2(2.2-11.4)$ & $1.83(1.31-2.6)$ & 0.01 \\
\hline Dysthymia & $0.8(0.2-3.5)$ & $0.8(0.51-1.3)$ & 0.98 \\
\hline OTHER ANXIETY DISORDERS & $53.1(44.3-61.7)$ & $16.2(14.7-18.0)$ & $<0.01$ \\
\hline Panic disorder & $2.6(1.0-6.6)$ & $0.3(0.1-0.6)$ & $<0.01$ \\
\hline Agoraphobia (without panic) & $13.2(7.4-22.4)$ & $2.0(1.5-2.7)$ & $<0.01$ \\
\hline Specific phobia & $23.5(16.6-32.1)$ & $9.4(8.3-10.6)$ & $<0.01$ \\
\hline Social phobia & $15.0(9.2-23.5)$ & $2.4(1.8-3.2)$ & $<0.01$ \\
\hline Generalised anxiety disorder & $13.2(7.7-21.8)$ & $2.7(2.1-3.4)$ & $<0.01$ \\
\hline Obsessive-compulsive disorder & $15.4(9.1-24.9)$ & $2.6(2.0-03.3)$ & $<0.01$ \\
\hline ALCOHOL & $7.4(4.1-13.2)$ & $3.0(2.3-3.8)$ & $<0.01$ \\
\hline Dependence syndrome & $6.8(3.5-12.7)$ & $1.6(1.1-2.0)$ & $<0.01$ \\
\hline Harmful use & $0.6(0.2-2.6)$ & $1.4(1.0-1.9)$ & 0.28 \\
\hline \multicolumn{4}{|l|}{ DUAL COMORBIDITY - PTSD + 2} \\
\hline Depression + Anxiety & $21.3(15.4-28.8)$ & $3.26(2.56-4.1)$ & $<0.01$ \\
\hline Depression + Alcohol & $2.6(0.7-9.1)$ & $0.44(0.25-0.8)$ & 0.01 \\
\hline Anxiety + Alcohol & $4.1(1.8-8.9)$ & $0.98(0.68-1.4)$ & $<0.01$ \\
\hline PTSD WITH COMORBIDITY & $67.6 \%(59.8-74.6)$ & ---- & ---- \\
\hline
\end{tabular}

\section{Temporal Relationship between PTSD and Comorbid Disorders}

Tables 4 and 5 show data concerning the temporal sequence of the disorders in individuals with PTSD using ICD-10 and DSM-IV diagnostic criteria respectively.

Most anxiety disorders began before the onset of PTSD, independently of using the ICD-10 or the DSM-IV criteria. In the case of depressive disorders, we observed a homogeneous distribution concerning prior, simultaneous or subsequent onset in relation to the PTSD onset when using ICD10 criteria (Table 4). However, when DSM-IV criteria were used, the onset of depressive disorders was predominately after PTSD (Table 5). For alcohol-related disorders, the onset was before the PTSD diagnosis in approximately half of the comorbid cases, without relevant differences for both classifications. 
Table 4. Proportion according to temporal relationship between comorbid diagnoses, using ICD-10 criteria.

\begin{tabular}{|c|c|c|c|c|}
\hline $\begin{array}{l}\text { DISORDER COMORBID WITH PTSD } \\
\text { (ICD-10) } \\
\text { COMORBIDITY (PAST } 12 \text { MONTHS) }\end{array}$ & N (\%) & $\begin{array}{l}\text { Comorbidity } \\
\text { before PTSD } \\
\text { onset } \\
\text { N (\%) }\end{array}$ & $\begin{array}{l}\text { Comorbidity } \\
\text { and PTSD } \\
\text { concurrent } \\
\text { (same year) } \\
\text { N (\%) }\end{array}$ & $\begin{array}{l}\text { Comorbidity } \\
\text { after PTSD } \\
\text { onset } \\
\text { N (\%) }\end{array}$ \\
\hline DEPRESSIVE DISORDERS & $98(100)$ & $34(34.7)$ & $27(27.6)$ & $37(37.8)$ \\
\hline Depressive episode & $74(100)$ & $23(31.1)$ & $25(33.8)$ & $26(35.1)$ \\
\hline Recurrent depression & $17(100)$ & $7(41.2)$ & $1(5.9)$ & $9(52.9)$ \\
\hline Dysthymia & $24(100)$ & $12(50.0)$ & $8(33.3)$ & $4(16.7)$ \\
\hline OTHER ANXIETY DISORDERS & $153(100)$ & 133 (86.9) & $5(3.3)$ & $15(9.8)$ \\
\hline Panic disorder & $9(100)$ & $5(55.6)$ & $1(11.1)$ & $3(33.3)$ \\
\hline Agoraphobia (without panic) & $35(100)$ & $24(68.6)$ & $5(14.3)$ & $6(17.1)$ \\
\hline Specific phobia & $65(100)$ & $53(81.5)$ & $4(6.2)$ & $8(12.3)$ \\
\hline Social phobia & $34(100)$ & $28(82.4)$ & $2(5.9)$ & $4(11.8)$ \\
\hline Generalised anxiety disorder & $28(100)$ & $17(60.7)$ & $4(14.3)$ & $7(25.0)$ \\
\hline Obsessive-compulsive disorder & $17(100)$ & $10(58.8)$ & $2(11.8)$ & $5(29.4)$ \\
\hline ALCOHOL & $21(100)$ & $12(57.1)$ & 3 (14.3) & $6(28.6)$ \\
\hline Dependence syndrome & $15(100)$ & $7(46.7)$ & $1(6.7)$ & $7(46.7)$ \\
\hline Harmful use* & $6(100)$ & $2(33.3)$ & $1(16.7)$ & $1(16.7)$ \\
\hline
\end{tabular}

Note: In the grouped categories as depressive disorders, other anxiety disorders, and alcohol-related disorders, in case of more than one comorbidity within the category, the one having earlier onset was used calculate the temporal relationship with PTSD. * Two cases with missing temporal data 
Table 5. Proportion according to temporal relationship between comorbid diagnoses, using DSM-IV criteria.

\begin{tabular}{|c|c|c|c|c|}
\hline COMORBIDITY (PAST 12 MONTHS) & $\begin{array}{l}\text { Total } \\
\mathrm{N}(\%)\end{array}$ & $\begin{array}{l}\text { Comorbidity } \\
\text { before PTSD }\end{array}$ & $\begin{array}{c}\text { Comorbidity } \\
\text { and PTSD } \\
\text { concurrent } \\
\text { (same year) } \\
\text { N (\%) }\end{array}$ & $\begin{array}{l}\text { Comorbidity } \\
\text { after PTSD }\end{array}$ \\
\hline DEPRESSIVE DISORDERS & $62(100)$ & $17(27.4)$ & $17(27.4)$ & $28(45.2)$ \\
\hline Depressive episode & $50(100)$ & $11(22.0)$ & $15(30.0)$ & $24(48.0)$ \\
\hline Recurrent depression & $11(100)$ & $6(54.5)$ & $1(9.1)$ & $4(36.4)$ \\
\hline Dysthymia & $2(100)$ & $1(50.0)$ & $1(50.0)$ & ---- \\
\hline OTHER ANXIETY DISORDERS & $89(100)$ & $79(88.8)$ & $3(3.4)$ & 7 (7.9) \\
\hline Panic disorder & $5(100)$ & $5(100)$ & ---- & ---- \\
\hline Agoraphobia (without panic) & $22(100)$ & $13(59.1)$ & $4(18.2)$ & $5(22.7)$ \\
\hline Specific phobia & $40(100)$ & $40(100)$ & ---- & ---- \\
\hline Social phobia & $24(100)$ & $16(66.7)$ & $1(4.2)$ & $7(29.1)$ \\
\hline Generalised anxiety disorder & $22(100)$ & $6(27.3)$ & $6(27.3)$ & $10(45.5)$ \\
\hline Obsessive-compulsivedisorder & $26(100)$ & $11(42.3)$ & $4(15.4)$ & $11(42.3)$ \\
\hline ALCOHOL & $11(100)$ & $6(54.5)$ & $1(9.1)$ & $4(36.4)$ \\
\hline Dependence syndrome & $9(100)$ & 3 (33.3) & $1(11.1)$ & $5(55.6)$ \\
\hline Harmful use & $2(100)$ & $1(50.0)$ & ---- & $1(50.0)$ \\
\hline
\end{tabular}

Note: In the grouped categories as depressive disorders, other anxiety disorders, and alcohol-related disorders, in case of more than one comorbidity within the category, the one having earlier onset was used calculate the temporal relationship with PTSD

\section{Discussion}

Our findings indicate that among indivi09s presenting PTSD comorbid with other anxiety disorders, the other anxiety disorders tend to precede PTSD. In the case of depression, no concentration was observed for the onset of cases in any period before, after or at the same time that PTSD started. The results demonstrate an important comorbidity of PTSD with depression, anxiety disorders and alcohol-related disorders which correlates with extensive body of literature studied (Engdahl et al., 1998; Ginzburg et al., 2010; Kessler and Chiu, 2005; Kessler et al., 2005, 1995; O’Toole et al., 1998; Viana et al., 2009).

Kessler et al. (2005) made an age-of-onset analysis using data from the National Comorbidity Survey Replication (Kessler et al., 2005). Comparing to our dataset, overall median age-of-onset using DSM-IV criteria for PTSD was 30.5 years old, 31 years old for depression and 14 years old for other anxiety disorders (excluding PTSD). Taking into account any anxiety (including PTSD), the median age-of-onset is 15 years old. Our results are consistent with the findings of the three studies mentioned before. Other anxiety disorders have an earlier median age-of-onset than PTSD, whilst depression has a median age-of-onset similar to PTSD's one. 
Our findings can also be examined in the light of the explanatory mechanisms first proposed by Breslau (Breslau, 2002) and summarised in the introduction. The first mechanism argues that patients previously diagnosed with another disorder are more likely to develop PTSD after a traumatic event. Our findings on comorbidity with anxiety disorder and, to a lesser extent, with alcohol-related disorders corroborate this mechanism. Although examining specific categories of anxiety reduces the number of observations, it is interesting to note that - in both the ICD-10 and the DSM-IV - specific phobia, social and agoraphobia have the most markedly earlier age-of-onset in relation to PTSD. These three disorders are related to the Internalising/Fear Factor, considered to be the underlying personality trait linked to anxiety disorders (Krueger and Markon, 2006; Miller et al., 2004). Depressive disorders did not have a predominance of prior or subsequent onset in comorbidity with PTSD and both the first and the second mechanism could underlie the cooccurrence of these disorders.

A longitudinal study with Israeli veterans from the Lebanese war (1980) evaluated the individuals in 1, 2 and 20 years after war experience. They observed that, amongst veterans presenting PTSD in the first evaluation, comorbidity (PTSD + Depression and PTSD + Anxiety) was higher in the subsequent evaluations. Double comorbidity (PTSD + depression + anxiety) became more prevalent than PTSD itself and PTSD comorbid with either depression and anxiety. They also found that PTSD predicted subsequent depression as well as anxiety, but not vice-versa. These findings corroborate the second mechanism, in which PTSD is a risk factor for other disorders (Ginzburg et al., 2010). In another cohort study, O'Toole et al. (1998) evaluated a sample of Australian Vietnam War Veterans and found that depression, agoraphobia, and simple phobia were risk factors for PTSD. Other anxious disorders as generalised anxiety disorder, panic disorder, and substance abuse were a consequence of PTSD. Social phobia, alcohol abuse had mixed etiology. Engdahl et al. (1998) made a cross-sectional study with American ex-prisoners of war and found that Depression was mostly secondary to PTSD (70.3\% of the cases). Alcohol Dependence/Abuse and agoraphobia had concurrent onset with PTSD, social phobia both concurrent and prior and panic disorder were both concurrent and secondary.

The last three publications mentioned above included only male military combatant populations, therefore limiting comparison with the population in the present study in which the population is mostly civilian with a slight predominance of women (57.7\%).

There are several discrepancies amongst the findings in different studies approaching the temporal relationship between comorbidities, making it difficult to refute any of the mechanism proposed by Breslau. One reason behind the contradictory findings is that most studies are crosssectional or rebuild temporality retrospectively (Ginzburg et al., 2010). Therefore, most publications explore the third mechanism, which attributes different patterns of comorbidity to factors prior to both diagnoses, rendering the individual susceptible to both disorders (i.e. PTSD and Depression). Latent personality traits (internalising and externalising) (Flory and Yehuda, 2015; Krueger et al., 2001; Krueger and Markon, 2006; Miller et al., 2004; Miller and Wolf, 2012) and childhood adversities (Hovens et al., 2012; Spinhoven et al., 2014) are the commonest explored factors to explain different patterns of comorbidity.

Spinhoven et al. (2014), explored the third mechanism using data from Dutch multicentre cohort study. Gender, childhood trauma (i.e., before age 16), neuroticism, low extroversion and severity of symptoms were associated with higher risk of comorbidity of depression and anxiety with PTSD. However, when the multivariate model was adjusted for sociodemographic variables, child neglect and clinical characteristics, neuroticism and extroversion lost their statistical significance. Female gender, sexual, and physical abuse are the most relevant risk factors for comorbidity with PTSD, although not exclusively, as these same risk factors were shared with anxious and depressive disorders. These findings are consistent with the shared vulnerability model 
for comorbidity of anxious and depressive disorders with PTSD (Spinhoven et al., 2014). Longitudinal studies, as the one carried out by Ginzburg et al. (Ginzburg et al., 2010), which have a lower risk of memory and temporal bias, also face difficulties about changes in classification throughout time. To avoid such problems, Ginzburg et al. used the same instrument, the "PTSD inventory," based on DSM-III (1980) criteria, in all of the measurement through the cohort, enabling more accurate comparison. From the first measurement in the study to the last, the DSM had gone through three different revisions, which inevitably compromises comparability.

Comorbidity has important implications regardless of the mechanism behind it. More recent findings show that patients with higher comorbidity have higher rates of suicide (Campbell et al., 2007; Galatzer-Levy et al., 2013; Ramsawh et al., 2014), lower quality of life (Araújo et al., 2014), worse psychosocial functioning (Campbell et al., 2007; Ginzburg et al., 2010), greater demand for services, worse response to anti-depressants (Campbell et al., 2007) and greater overall severity (Campbell et al., 2007; Kessler and Chiu, 2005). Such findings should be considered by both specialized services and primary care services. Patients with PTSD associated with other diagnosis require more attention in primary care and should, therefore, have a lower threshold for referral to specialized services.

In our study, we found a high prevalence of PTSD with anxiety and depression disorders. Comorbid cases prognosis tends to show poorer prognosis compared to non-comorbid cases. This fact has significant implications for treatment and also to therapeutic research. As most clinical trials emphasize single diagnosis, or have comorbidity as an exclusion criterion (Dennis et al., 2015; Fortin et al., 2006; Zimmerman et al., 2005, 2002) they might not address the difficulty of treating comorbid cases, which represent a large proportion of the patients with PTSD (Galatzer-Levy et al., 2013; Kessler and Chiu, 2005; Kessler et al., 1995). This problem is even worst those people looking for specialized service, as they tend to present an even higher proportion of comorbid cases (Araújo et al., 2014; Zimmerman et al., 2002)

In conclusion, the problem of comorbid cases of PTSD is not restricted to clinical populations as our study demonstrates in a large representative sample of two larger cities. It is necessary to evaluate the co-occurrence of other mental disorders among PTSD patients and to start including them in therapeutic studies to look for more efficient treatments.

\section{Limitations}

Some study weaknesses have to be acknowledged. The cross-sectional design imposes limitations on establishing a temporal relationship between onsets of psychiatric disorders due to memory bias.

Collection bias can also compromise the estimation of time of onset of comorbidities. Responders were asked about the age-of-onset of each disorder, but not the month. So, in the category "concurrent" diagnoses the disorders occurring in the same year might not be simultaneous. This collection bias is minimised when considering onset prior to or after PTSD. Crosssectional studies, that reconstruct time of the onset retrospectively, use age-of-onset considering that subjects would not be able to recall the month of onset with precision (Cía et al., 2018; Kessler and Chiu, 2005; Viana and Andrade, 2012).

Data took into account only the symptoms related to the worst event. More recent literature (Priebe et al., 2018) shows that when index trauma included multiple events, severity scores are significantly higher. Since our study considers the diagnosis of PTSD regardless of severity, we think that the effect of this limitation on our results is minimized. 
The survey didn't include data on treatment which could also change the course and duration of the disorders evaluated. The ones without comorbidity, for example, could be the ones that were treated earlier in the course of the illness.

The diagnoses were based on the CIDI 2.1, which is a lay-administered questionnaire that can lead to a certain degree of misclassification. Our study did not include the CIDI 2.1 category of psychotic disorders. Nevertheless, we think this represents a very small fraction of the sample considering that Perälä et al. found that 3.06 to $3.96 \%$ of the general population suffers from psychotic disorders (Perälä et al., 2007).

\section{Competing Interests}

Bressan reports, during the conduct of the study: grants, personal fees and non-financial support from Janssen, personal fees from Aché Laboratórios Farmacêuticos, grants and personal fees from Roche, outside the submitted work.

The other authors declare that they have no competing interests.

\section{Acknowledgments}

This study was supported by the State of São Paulo Funding Agency (FAPESP) by the Grant: 2004/15039-0, and the National Research Council (CNPq) by the Grant 420122/2005-2. WSR is funded by the European Research Council under the European Union's Seventh Framework Programme (FP7/2007-2013)/ERC grant agreement number [337673]. Bressan reports grants and non-financial support from Fundação de Amparo à Pesquisa de São Paulo (FAPESP/2016/02246-

5), Brasil; grants and non-financial support from Conselho Nacional de Desenvolvimento Científico e Tecnologia (307077/2013-6, CNPq), Brasil, personal fees and nonfinancial support from Coordenação de Aperfeiçoamento de Pessoal de Nível Superior (CAPES). Longo MSC would like to thank Samuel Harrison for his help in the revision of the English version of the manuscript.

\section{References}

American Psychiatric Association, 1994. Diagnostic and statistical manual of mental disorders : DSM-IV., 4th ed. ed. American Psychiatric Association, Washington, DC.

Andreoli, S.B., Ribeiro, W.S., Quintana, M.I., Guindalini, C., Breen, G., Blay, S.L., Coutinho, E.S.F., Harpham, T., Jorge, M.R., Lara, D.R., Moriyama, T.S., Quarantini, L.C., Gadelha, A., Vilete, L.M.P., Yeh, M.S.L., Prince, M., Figueira, I., Bressan, R. a, Mello, M.F., Dewey, M.E., Ferri, C.P., Mari, J.D.J., 2009. Violence and post-traumatic stress disorder in Sao Paulo and Rio de Janeiro, Brazil: the protocol for an epidemiological and genetic survey. BMC Psychiatry 9, 34. https://doi.org/10.1186/1471-244X-9-34

Araújo, A.X., Berger, W., Coutinho, E.S.F., Marques-Portella, C., Luz, M.P., Cabizuca, M., Fiszman, A., Figueira, I., Mendlowicz, M.V., 2014. Comorbid depressive symptoms in treatmentseeking PTSD outpatients affect multiple domains of quality of life. Compr. Psychiatry 55, 56- 
63. https://doi.org/10.1016/j.comppsych.2013.09.004

Breslau, N., 2002. Epidemiologic studies of trauma, posttraumatic stress disorder, and other psychiatric disorders. Can. J. Psychiatry 47, 923-929.

Breslau, N., Davis, G.C., Peterson, E.L., Schultz, L., 1997. Psychiatric sequelae of posttraumatic stress disorder in women. Arch. Gen. Psychiatry 54, 81-7.

Campbell, D.G., Felker, B.L., Liu, C.F., Yano, E.M., Kirchner, J.E., Chan, D., Rubenstein, L. V., Chaney, E.F., 2007. Prevalence of depression-PTSD comorbidity: Implications for clinical practice guidelines and primary care-based interventions. J. Gen. Intern. Med. 22, 711-718. https://doi.org/10.1007/s11606-006-0101-4

Cía, A.H., Stagnaro, J.C., Aguilar Gaxiola, S., Vommaro, H., Loera, G., Medina-Mora, M.E., Sustas, S., Benjet, C., Kessler, R.C., 2018. Lifetime prevalence and age-of-onset of mental disorders in adults from the Argentinean Study of Mental Health Epidemiology. Soc. Psychiatry Psychiatr. Epidemiol. 53, 341-350. https://doi.org/10.1007/s00127-018-1492-3

Connor, K.M., Davidson, J.R.T., 1997. Familial Risk Factors in Posttraumatic Stress Disorder. Ann. N. Y. Acad. Sci. 821, 35-51. https://doi.org/10.1111/j.1749-6632.1997.tb48267.x

Dennis, B.B., Roshanov, P.S., Naji, L., Bawor, M., Paul, J., Plater, C., Pare, G., Worster, A., Varenbut, M., Daiter, J., Marsh, D.C., Desai, D., Samaan, Z., Thabane, L., 2015. Opioid substitution and antagonist therapy trials exclude the common addiction patient: a systematic review and analysis of eligibility criteria. Trials 16, 475. https://doi.org/10.1186/s13063-015-0942-4

Engdahl, B., Dikel, T.N., Eberly, R., Blank, A., 1998. Comorbidity and course of psychiatric disorders in a community sample of former prisoners of war. Am. J. Psychiatry 155, 1740-1745. https://doi.org/10.1176/ajp.155.12.1740

Flory, J.D., Yehuda, R., 2015. Comorbidity between post-traumatic stress disorder and major depressive disorder: alternative explanations and treatment considerations. Dialogues Clin. Neurosci. 17, 141-50.

Fortin, M., Pinho, G., Gignac, J., Almirall, J., Lapointe, L., Dionne, J., 2006. Randomized controlled trials : do they have external validity for patients with multiple comorbidities ? Ann. Fam. Med. 4, 104-108. https://doi.org/10.1370/afm.516.INTRODUCTION

Franklin, C.L., Zimmerman, M., 2001. Posttraumatic stress disorder and major depressive disorder: investigating the role of overlapping symptoms in diagnostic comorbidity. J. Nerv. Ment. Dis. $189,548-51$.

Franko, D.L., Thompson, D., Barton, B.A., Dohm, F.-A., Kraemer, H.C., lachan, R., Crawford, P.B., Schreiber, G.B., Daniels, S.R., Striegel-Moore, R.H., 2005. Prevalence and comorbidity of major depressive disorder in young black and white women. J. Psychiatr. Res. 39, 275-83. https://doi.org/10.1016/j.jpsychires.2004.08.010

Friedman, M.J., Yehuda, R., 1995. Post-traumatic stress disorder and comorbidity: Psychobiological approaches to differential diagnosis, in: Friedman, M.J., Charney, D.S. (Eds.), Neurobiological 
and Clinical Consequences of Stress: From Normal Adaptation to Post Traumatic Stress Disorder. Lippincott Williams \& Wilkins Publishers, pp. 429-445.

Galatzer-Levy, I.R., Nickerson, A., Litz, B.T., Marmar, C.R., 2013. Patterns of Lifetime Ptsd Comorbidity: a Latent Class Analysis. Depress. Anxiety 30, 489-496. https://doi.org/10.1002/da.22048

Ginzburg, K., Ein-Dor, T., Solomon, Z., 2010. Comorbidity of posttraumatic stress disorder, anxiety and depression: A 20-year longitudinal study of war veterans. J. Affect. Disord. 123, 249-257. https://doi.org/10.1016/j.jad.2009.08.006

Hovens, J.G.F.M., Giltay, E.J., Wiersma, J.E., Spinhoven, P., Penninx, B.W.J.H., Zitman, F.G., 2012. Impact of childhood life events and trauma on the course of depressive and anxiety disorders. Acta Psychiatr. Scand. 126, 198-207. https://doi.org/10.1111/j.16000447.2011.01828.x

Jordan, B.K., Schlenger, W.E., Hough, R., Kulka, R.A., Weiss, D., Fairbank, J.A., Marmar, C.R., 1991. Lifetime and current prevalence of specific psychiatric disorders among Vietnam veterans and controls. Arch. Gen. Psychiatry 48, 207-15.

Kessler, R., Chiu, W., 2005. Prevalence, Severity, and Comorbidity of Twelve-month DSM-IV Disorders in the National Comorbidity Survey Replication (NCS- R). Arch. Gen. Psychiatry 62, 617-627. https://doi.org/10.1001/archpsyc.62.6.617.Prevalence

Kessler, R.C., Berglund, P., Demler, O., Jin, R., Merikangas, K.R., Walters, E.E., 2005. Lifetime Prevalence and Age-of-Onset Distributions of DSM-IV disorders in the National Comorbidity Survey Replication. Arch Gen Psychiatry 62, 593-602. https://doi.org/10.1001/archpsyc.62.6.593

Kessler, R.C., Sonnega, A., Bromet, E., Hughes, M., Nelson, C.B., 1995. Posttraumatic Stress Disorder in the national comorbidity survey. Arch. Gen. Psychiatry 52, 1048-1060. https://doi.org/10.1001/archpsyc.1995.03950240066012

Krueger, R.F., Markon, K.E., 2006. Reinterpreting comorbidity: a model-based approach to understanding and classifying psychopathology. Annu. Rev. Clin. Psychol. 2, 111-133. https://doi.org/10.1146/annurev.clinpsy.2.022305.095213

Krueger, R.F., McGue, M., lacono, W.G., 2001. The higher-order structure of common DSM mental disorders: internalization, externalization, and their connections to personality. Pers. Individ. Dif. 30, 1245-1259. https://doi.org/10.1016/S0191-8869(00)00106-9

Kulka, R., Schlenger, W.E., Fairbank, J.A., Hough, R.L., Jordan, B.K., 1990. Trauma and the Vietnam War Generation: Report of Findings from the National Vietnam Veterans Readjustment Study. Brunner/Mazel. https://doi.org/10.1097/00005053-199110000-00024

Labbate, L.A., Sonne, S.C., Randal, C.L., Anton, R.F., Brady, K.T., 2004. Does comorbid anxiety or depression affect clinical outcomes in patients with post-traumatic stress disorder and alcohol use disorders? Compr. Psychiatry 45, 304-10. https://doi.org/10.1016/j.comppsych.2004.03.015 
Miller, M.W., Kaloupek, D.G., Dillon, A.L., Keane, T.M., 2004. Externalizing and internalizing subtypes of combat-related PTSD: a replication and extension using the PSY-5 scales. J. Abnorm. Psychol. 113, 636-645. https://doi.org/10.1037/0021-843X.113.4.636

Miller, M.W., Wolf, E.J., 2012. Personality and the latent structure of PTSD comorbidity. J Anxiety Disord 29, 997-1003. https://doi.org/10.1016/j.biotechadv.2011.08.021.Secreted

Mills, K.L., Teesson, M., Ross, J., Peters, L., 2006. Trauma, PTSD, and substance use disorders: findings from the Australian National Survey of Mental Health and Well-Being. Am. J. Psychiatry 163, 652-658. https://doi.org/10.1176/appi.ajp.163.4.652

O'Toole, B.I., Marshall, R.P., Schureck, R.J., Dobson, M., 1998. Posttraumatic stress disorder and comorbidity in Australian Vietnam veterans: risk factors, chronicity and combat. Aust. N. Z. J. Psychiatry 32, 32-42. https://doi.org/10.1046/j.1440-1614.1998.00368.x

Perälä, J., Suvisaari, J., Saarni, S.I., Kuoppasalmi, K., Isometsa, E., Pirkola, S., Partonen, T., TuulioHenriksson, A., Hintikka, J., Kieseppa, T., Harkanen, T., Koskinen, S., Lonnqvist, J., 2007. Lifetime Prevalence of Psychotic and Bipolar I Disorders in a General Population. Arch. Gen. Psychiatry 64, 19-28.

Priebe, K., Kleindienst, N., Schropp, A., Dyer, A., Krüger-Gottschalk, A., Schmahl, C., Steil, R., Bohus, M., 2018. Defining the index trauma in post-traumatic stress disorder patients with multiple trauma exposure: impact on severity scores and treatment effects of using worst single incident versus multiple traumatic events. Eur. J. Psychotraumatol. 9, 1486124. https://doi.org/10.1080/20008198.2018.1486124

Quintana, M.I., Gastal, F.L., Jorge, M.R., Miranda, C.T., Andreoli, S.B., 2007. Validity and limitations of the Brazilian version of the Composite International Diagnostic Interview (CIDI 2.1). Rev. Bras. Psiquiatr. 29, 18-22. https://doi.org/10.1590/S1516-44462006005000024

Quintana, M.I., Mari, J. de J., Ribeiro, W.S., Jorge, M.R., Andreoli, S.B., 2012. Accuracy of the Composite International Diagnostic Interview (CIDI 2.1) for diagnosis of post-traumatic stress disorder according to DSM-IV criteria. Cad. Saude Publica 28, 1312-1318. https://doi.org/10.1590/S0102-311X2012000700009

Ramsawh, H.J., Fullerton, C.S., Mash, H.B.H., Ng, T.H.H., Kessler, R.C., Stein, M.B., Ursano, R.J., 2014. Risk for suicidal behaviors associated with PTSD, depression, and their comorbidity in the U.S. Army. J. Affect. Disord. 161, 116-22. https://doi.org/10.1016/j.jad.2014.03.016

Ribeiro, W.S., Mari, J.D.J., Quintana, M.I., Dewey, M.E., Evans-Lacko, S., Vilete, L.M.P., Figueira, I., Bressan, R.A., de Mello, M.F., Prince, M., Ferri, C.P., Coutinho, E.S.F., Andreoli, S.B., 2013. The Impact of Epidemic Violence on the Prevalence of Psychiatric Disorders in Sao Paulo and Rio de Janeiro, Brazil. PLoS One 8. https://doi.org/10.1371/journal.pone.0063545

Solomon, Z., Bleich, A., 1998. Comorbidity of Posttraumatic Stress Disorder and Depression in Israeli Veterans. CNS Spectr. 3, 15-21. https://doi.org/10.1017/S1092852900007288

Spinhoven, P., Penninx, B.W., van Hemert, A.M., de Rooij, M., Elzinga, B.M., 2014. Comorbidity of PTSD in anxiety and depressive disorders: Prevalence and shared risk factors. Child Abus. 
Negl. 38, 1320-1330. https://doi.org/10.1016/j.chiabu.2014.01.017

Spitzer, R.L., Williams, J.B., Gibbon, M., First, M.B., 1992. The Structured Clinical Interview for DSM-III-R (SCID). I: History, rationale, and description. Arch. Gen. Psychiatry 49, 624-9.

Stein, M.B., McQuaid, J.R., Pedrelli, P., Lenox, R., McCahill, M.E., 2000. Posttraumatic stress disorder in the primary care medical setting. Gen. Hosp. Psychiatry 22, 261-9.

Viana, M.C., Andrade, L.H., 2012. Lifetime Prevalence, Age and Gender Distribution and Age-ofOnset of Psychiatric Disorders in the São Paulo Metropolitan Area, Brazil: Results from the São Paulo Megacity Mental Health Survey. Rev. Bras. Psiquiatr. 34, 249-260. https://doi.org/10.1016/j.rbp.2012.03.001

Viana, M.C., Teixeira, M.G., Beraldi, F., Bassani, I.D.S., Andrade, L.H., 2009. São Paulo Megacity Mental Health Survey - A population-based epidemiological study of psychiatric morbidity in the São Paulo Metropolitan Area : aims, design and field implementation São Paulo Megacity - Um estudo epidemiológico de base populacional aval. Rev. Bras. Psiquiatr. 31, 375-386.

World Health Organization., 1997. Composite International Diagnostic Interview (CIDI) researcher's manual : version 2.1. World Health Organization, Geneva, Switzerland.

World Health Organization, 1992. The ICD-10 Classification of Mental and Behavioural Disorders. Int. Classif. 10, 1-267. https://doi.org/10.1002/1520-6505(2000)9:5<201::AIDEVAN2>3.3.CO;2-P

Yehuda, R., McFarlane, A., Shalev, A., 1998. Predicting the development of posttraumatic stress disorder from the acute response to a traumatic event. Biol. Psychiatry 44, 1305-1313. https://doi.org/10.1016/S0006-3223(98)00276-5

Zimmerman, M., Chelminski, I., Posternak, M.A., 2005. Generalizability of antidepressant efficacy trials: differences between depressed psychiatric outpatients who would or would not qualify for an efficacy trial. Am. J. Psychiatry 162, 1370-2. https://doi.org/10.1176/appi.ajp.162.7.1370

Zimmerman, M., Mattia, J.I., Posternak, M. a., 2002. Are Subjects in Pharmacological Treatment Trials of Depression Representative of Patients in Routine Clinical Practice? Am. J. Psychiatry 159, 469-473. https://doi.org/10.1176/appi.ajp.159.3.469 
